John R Ashton, CBE Carlos Alvarez Dardet Joint Editors

\section{PLENTY TO THINK ABOUT ON FOOD AND THE ENVIRONMENT}

In this bumper issue we carry an important debate about the persistent organic pollutants and their health effects. Writing this at the end of summer, I'm struck by the fact that this year I have seen sparrows twice. Once in the Yorkshire Dales and once on Martha's Vineyard. I can't remember the last time I saw sparrows in Manchester or Liverpool. In Rachel Carson's book Silent Spring, which was published in the early 1960s, one chapter is called "Where no bird sings". Forty years later our set of papers pick up the real and continuing impact of what Rachel Carson's talking about. The persistence of organic pollutants in our environment, their ability to travel long distances, to turn up in polar regions and extreme bits of the food chain, have consequences for human and animal health, which we are still trying to resolve.

The centre piece of our debate is a paper by Schafer and Kegley in which they review the extent of persistent toxic chemicals in the US food supply in the aftermath of the Stockholm Convention on persistent chemicals. While the Convention is to be welcomed and should over time reduce the further addition to the chemical cocktail that now pervades our food chain, as of August 2002 only 16 countries had ratified it. As the author's indicate American dining tables are riddled with organic chemicals, readers will make up their own mind about the rebuttal of Schafer and Kegley's paper by the US Food and Drug Administration and seven further papers contribute a range of perspectives to what should be an important public health debate.

See pages 813-34

\section{www.jech.com}

Ironically, and also in this issue, we have a leader from Stephen Dealler on the British BSE Inquiry report. Dealler was one of those lone early voices trying to draw attention to the unfolding scandal. As he points out, if the newly established Food Standards Agency for England had been in charge for BSE the agency would have needed to take long term decisions despite the immediate economic damage and should have listened to medical advice even though it was bad news. Dealler goes on to point out that BSE has made it clear that because of the way in which new food manufacturing techniques are introduced, growing potential inadequately understood, public health risks may appear but the economic pressure to take those risks will grow also.

See page 803

Miquel Porta in our Speaker's corner links the two issues and raises the question of public health governance in relation to these kinds of questions.

See page 806

Completing the food and nutrition theme this month is an editorial from India linked to a research paper on body mass index in urban adults by Shulka and colleagues. The paradox of the coexistence of undernutrition and obesity is explored and Geoffrey Rose's seminal insight into population prevention is challenged when public health problems are occurring at both ends of the curve.

See pages 804,876

Another highlight of this issue is a useful and timely glossary on medical informatics and a unifying lecture by the English Chief Medical Officer, Professor Sir Liam Donaldson, looking at health services and public health in the round. The editors are keen to carry more monthly lectures as part of our commitment to continuing medical education and would welcome submission of significant practice for publication.

See pages 835

One of the features of the current health services developed in England has been the development of National Service Frameworks for health care. These are rational and systematic efforts to ensure evidence based quality care for specific conditions and population groups within a public health framework. These have been produced for heart disease, cancer, mental health, and one that is focused on the population group, namely older people, is described by its author Dr Philp.

\section{See page 841}

Our Theory and Methods section includes an interesting new elaboration of an approach to measuring the health burden of chronic disease and a stimulating contribution from the US describes an ecological model for conceptualising communities bringing together data from a number of sectors other than health services.

See page 843 